book review

\title{
Big Data, Small Media
}

GRANT BOLLMER

UNIVERSITY OF SYDNEY

Andrew Dubber

Radio in the Digital Age

Polity, Cambridge, 2013

ISBN 9780745661971

RRP US $\$ 31.95$

Charles Ess

Digital Media Ethics, Second Edition

Polity, Cambridge, 2014

ISBN 9780745656069

RRP US $\$ 33.95$

Graeme Kilpatrick

Computer Games and the Social Imaginary

Polity, Cambridge, 2013

ISBN 9780745641119

RRP US\$31.95

ISSN 1837-8692

Cultural Studies Review 2014. (c) 2014 Grant Bollmer. This is an Open Access article distributed under the terms of the Creative Commons Attribution 4.0 Unported (CC BY 4.0) License

(https://creativecommons.org/licenses/by/4.0/), allowing third parties to copy and redistribute the material in any medium or format and to remix, transform, and build upon the material for any purpose, even commercially, provided the original work is properly cited and states its license.

Citation: Cultural Studies Review (CSR) 2014, 20, 4087, http://dx.doi.org/10.5130/csr.v20i2.4087 


\author{
Dhiraj Murthy \\ Twitter: Social Communication in the Twitter Age \\ Polity, Cambridge, 2013 \\ ISBN 9780745652399 \\ RRP US $\$ 33.95$ \\ Jill Walker Rettberg \\ Blogging, Second Edition \\ Polity, Cambridge, 2013 \\ ISBN 9780745663654 \\ RRP US\$31.95
}

What is the relationship between culture and technology? For many within cultural studies, the usual position is to suggest that technology is in some way subservient to human intention, its ultimate function shaped by creative audiences and consumers. The proliferation of technologies in everyday life, through social media, smartphones and various other internet associated devices, has problematised this view as it's increasingly clear that non-human things play a massive role in producing and mediating whatever it is we can define as culture. Let me begin with an example that may seem banal but directly cuts to claims we, as cultural studies scholars, have towards understanding our disciplinary object of 'culture'. Google's $n$ gram Viewer is a statistical tool designed to data mine the massive archive of published texts accumulated as Google Books. It was created, in part, to use Google Books to advance a quantitative science of culture dubbed 'culturomics' by its creators, Harvard-affiliated Erez Aiden and Jean-Baptiste Michel, ${ }^{1}$ and promoted in the pages of Science as a way to 'open books to new cultural studies' through computational methods derived from evolutionary biology. ${ }^{2}$ Aiden and Michel see the ubiquity of Big Data as that which will render the seemingly subjective claims of the humanities a thing of the past, plotting the data-driven truth of culture that has been, to use the title of their popular book, Uncharted until now. ${ }^{3}$

An $n$-gram visualises the occurrence of a specific phrase in the entire corpus of Google Books, measured by year, normalised in relation to books published annually, all in accordance with what's in Google's database. In Figure 1 I've plotted 
the terms 'cultural studies', 'critical theory', 'media studies', and 'digital humanities' in the $n$-gram Viewer. 'Cultural studies' peaked in English-language books around 2003, after which it dropped at a troubling rate. 'Critical theory' has fared no better-it peaked in 1994 and waned from print since. 'Cultural studies' has vastly surpassed 'critical theory' in Google's corpus since the early 1990s, and both exceeded 'media studies'. So what does this $n$-gram tell us? While Aiden and Michel infer that this kind of study can scientifically reveal the truth of culture, I see their method as a reinvention of quantitative content analysis in an age of data analytics, where computers count words as humans did previously, albeit with a scale unmatched prior to Big Data. My example may simply reveal that people who write about cultural studies use the phrase 'cultural studies' more than people who write about critical theory use 'critical theory'. The meaning of a specific phrase is dependent on context in a way not revealed by the $n$-gram Viewer. The limits of available data shape the possibilities for analysis, which are inevitably read according to an interpretive heuristic, acknowledged or not. The absence of the 'digital humanities' from the figure is partially because the $n$-gram Viewer only charts books and its data stops at 2008. Yet the limits of data science are often obscured in favour of an ideological totality in which whatever is available online is assumed to represent all that exists.

It's not as if an n-gram reveals nothing; it reveals more about the politics of truth than about any actual claim to truth, however. The ability to articulate 'cultural

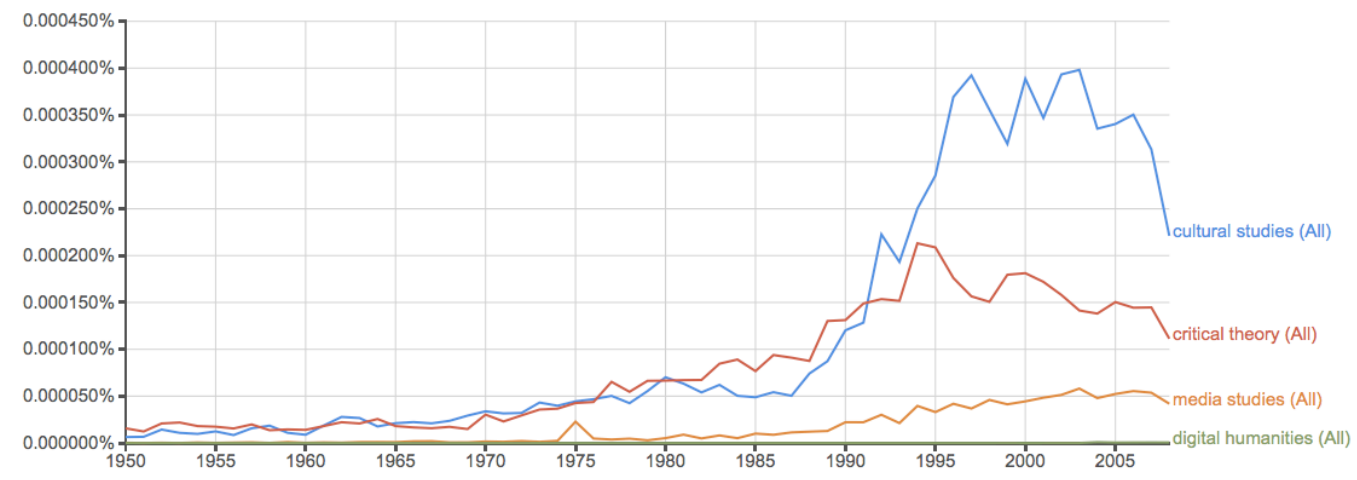

Figure 1: A Google $n$-Gram charting the relative frequency of the phrases 'cultural studies', 'critical theory', 'media studies', and 'digital humanities' in the Google Books corpus 
studies' as a specific practice depends on understanding the relationship culture has with technology, along with the digital methodologies increasingly applied to 'objectively' understand culture. The mere existence of methods embodied by the $n$ gram Viewer, from which its designers argue a new science of culture will come into being for the first time (and can be called 'cultural studies', apparently), tells us that cultural studies scholars must engage with technological questions of method, quantification, computerisation and standardisation, even when one's object of study has no overt association with technology. These problems carry with them more than an echo of past debates. Yet cultural studies scholars have often resisted discussions of the power of computers in shaping culture, or, worse, reduced new media to little more than new locations for active audiences' participation. ${ }^{4}$ The knowledge we produce-which should not inherently exclude these new technologies in the name of a mythical purity projected onto hermeneutic and qualitative research-must be made to give better accounts of the technological and cultural conditions of knowledge production, alongside the assumptions involved when categories like 'the technological' and 'the cultural' stand in for functions that legitimise and evaluate forms of knowledge.

Because technical knowledge is often associated with a pre-professional reframing of higher education, cultural studies scholars must also engage in the classroom setting with these same questions. It no longer seems-if it ever really was-that the university is willing to support forms of knowledge that cannot easily be articulated to techno-scientific means of advancing 'practical' experience that either teaches students 'skills' or results in the influx of grant-based funding. Obviously, there is an extensive history that I'm glossing over, especially since one could argue that the function of the university throughout Western modernity has been to produce a kind of bourgeois citizen and, in its very instantiation, the project of cultural studies has often been anathema to the institution of higher education. ${ }^{5}$ Itself a point of articulation in debates about the value of academic research, the limits of theory and the teaching of skills designed to prepare students for a world of technologically informed creative labour, cultural studies must once again reflect on its specificity as a political knowledge practice designed to intervene in specific historical conjunctures. And, I want to suggest, a large part of these problems has to do with cultural studies' association with media studies. 
The linking of cultural studies to media studies emerges out of a specific institutional and political formation into which cultural studies intervened in the 1970s, 1980s and 1990s. In its concern for the popular as a locus of political agency, cultural studies often looked to the signifying practices of media representation as a field in which to theorise a possibility for collective struggle in the everyday lives of individuals. At the same time, the study of media and communication expanded because it served as a quasi-professional field for training journalists, public relations professionals and workers in the creative industries. Enrolments in media and communications departments increased because of the skills a degree in communications supposedly provides for students who desire to work in media, providing qualifications for entry into an increasingly structured yet precarious workforce. ${ }^{6}$ Consequently, cultural studies practitioners who study media have often passed as those who produce 'useful' knowledge for students who desire jobs in cultural industries. In the process the two fields were equated institutionally, 'as if', to follow Lawrence Grossberg, 'cultural studies were the study of media (and popular) culture, and media studies necessarily embodied the project of cultural studies'.7

The teaching practice of media studies has, through its disciplinary emphasis on understanding and producing media, narrowed the focus of cultural studies because of the orientation demanded of cultural studies scholars through research evaluation frameworks and the job market, biasing hiring towards those prepared to teach certain courses with relatively standardised canons. The amalgamation of media studies and cultural studies has resulted in decades of articles that examine similar creative practices as if the contemporary context has remained static. For instance, countless investigations of social media today-from left activists and neoliberals alike-do little more than celebrate the empowerment of individuals producing culture outside the boundaries of market exchange, repeating decades of cultural studies work on television and film audiences, from the 'encoding/decoding' model onwards.

Because of cultural studies' inability to produce new narratives about media culture, Grossberg argues that it should potentially abandon the focus on media altogether: 'The question is, at least for cultural studies: In what way is the concept of media a useful concept around which to organize research on the conjuncture?'8 
From within media studies, new subfields and theoretical paradigms like media archaeology, media ecology and object-oriented ontology seem to ask a similar question, if from the reverse perspective: how useful is 'culture' for studying media, especially since cultural studies-type work seems to simply restate the centrality of human agency and ignore the material power of the technological? Intervening in today's context would seem to demand a different way of approaching mediawhich means both research and teaching on media in cultural studies must be rethought to reassert the primacy of cultural studies' commitment to radical contexualism.

In recent years, Polity's Digital Media and Society series has become a fielddefining standard in overviews of new media, often derived not from the traditions of cultural studies but from sociology - which suggests that the link between media studies and cultural studies may simply be dissolving organically because of many cultural studies' scholars unwillingness to engage with the technological in serious depth. Books in the series walk the line between research monograph and textbook, of interest to postgraduates and researchers but also suitable as set readings for undergraduate courses on media. The books are often written by major theorists and researchers in the field and the series is full of texts that define specific concepts, platforms, or institutions, giving nuanced genealogies of cultural and social theory in relation to present technologies. Books in the series regularly review research on a specific topic to provide an easy introduction to students and scholars interested in any number of major subjects, from YouTube to New Media Activism.

There is no uniform model for the volumes in the series. Of the specific books surveyed for this review, Charles Ess's Digital Media Ethics is clearly a textbook while Graeme Kirkpatrick's Computer Games and the Social Imaginary engages with theoretical arguments not inherently intended for students. Jill Walker Rettberg's Blogging and Dhiraj Murthy's Twitter give substantive overviews of a specific technology and associated controversies. They would well serve students interested in the titular subjects and could potentially help researchers review some of the literature on these topics. Andrew Dubber's Radio in the Digital Age provides a primer in how to think about technological change using radio as a locus for a number of cultural and theoretical issues. While not explicitly written as a textbook, 
I feel Radio in the Digital Age provides one of the finest introductions available for thinking about technology from a cultural studies perspective.

If, as I've suggested above, cultural studies needs to turn its attention to the technological in the production and shaping of knowledge, and to understanding 'media' in ways that do not simply reproduce decades-old narratives about audience empowerment, then Radio in the Digital Age would be an outstanding beginning for thinking about the sheer complexity of the technological without reducing it to any singular dimension, emphasising instead how technology is necessarily articulated into broader contexts. It provides an invaluable model for thinking about technology that would be suitable not only for undergraduates, but also for anyone interested in how to conceptualise technology in a way that emphasises both complexity and specificity.

In Radio in the Digital Age, Dubber confronts the challenges digital technologies have levelled at his eponymous medium to investigate how technological change opens up countless questions about how we conceptualise seemingly obvious and mundane technologies in everyday life: 'My contention is that radio is something specific', he states, 'but that its specificity is to be located by examining the consistencies that are present within those changing discursive practices that surround it.' (15) And these practices are manifold. How can we understand what radio is and what it does given the technological, cultural, and social articulations surrounding its use? Can we think of radio only as a material technology, a thing that transmits sound from one place to another? Or is radio the many social practices and techniques involved with listening? What about the issues of regulation and economy associated with the changes produced by the Internet? Are podcasts radio? Is Spotify? Given that what we think of as radio today is vastly different than what it was in the past, what, exactly, is radio? Dubber explores these questions-and many others-and refuses to give simple answers. He instead allows these questions to intersect and diffract, demonstrating how radio is an assemblage that changes in relation to different contexts, irreducible to either human practices or technological form. Understanding radio, in the end, reveals far more about the context of the digital than about whatever we can define as radio, because radio cannot be isolated from cultural, technological, social and economic processes. 
Dubber's refusal to give simple answers, always leading back to questions of context, is what makes Radio in the Digital Age such a strong book. Similarly, Charles Ess's Digital Media Ethics is another textbook that should be acclaimed because it refuses easy answers and instead calls on students to look at technology from numerous, often contradictory, perspectives. Digital Media Ethics is intended as an introduction to various schools of ethical philosophy, applied to specific cases and controversies related to the internet and social media, from privacy to pornography and beyond. Unlike Radio in the Digital Age, I do not think that Digital Media Ethics could be mistaken for a work of cultural studies given its attention to utilitarianism, deontological ethics and virtue ethics, among other schools of thought. The study of ethics, after all, is often neglected in cultural studies because of an unwillingness to serve as a moral arbiter, to define the true and the good when things are usually more complicated than any one reductive system of difference. Yet this stance, as Ess makes clear, has an implicit system of ethics attached to it. Ess doesn't tell anyone what to think. In the process, he develops a textbook that opens up discussion that emphasises the difficulty of evaluating technology's role in shaping culture and is filled with complicated examples designed to provoke active classroom discussion. Both Radio in the Digital Age and Digital Media Ethics would probably frustrate anyone looking for clear judgments on what technology is doing (and would potentially annoy students looking for easy answers to difficult questions), but they provide outstanding introductions to thinking about technology that could orient students (and researchers) towards larger contextual articulations.

I get the impression that Dubber's and Ess's books are exceptional, however. These books give general overviews that inevitably lead to questions-not answers-about ontology, epistemology, axiology and the politics intrinsic to these philosophical categories. In these two books, technologies do not have clear, defined boundaries; both authors point towards the difficulties involved with making claims about what technologies are and do. This is not the case for all of the books in the New Media and Society series-though, I should state, this is not inherently a criticism. Dhiraj Murthy's Twitter and Jill Walker Rettberg's Blogging both examine a specific form of participatory media and give an overview of the history and issues surrounding these technologies' position in contemporary life. These two books follow a similar model. They give historical and theoretical context to their titular 
media before delving into the many issues and controversies surrounding that medium's use. Blogging begins by positioning blogs in relation to the McLuhanite teleology of orality, literacy and second orality, before discussing topics such as citizen journalism, branding and the use of blogs as a way of narrating the self. Twitter, similarly, provides a historical and theoretical perspective through which to understand the technology, derived from McLuhan, Heidegger and Erving Goffman, among others, before examining Twitter's use in disasters, activism, public health and, like Blogging, citizen journalism. These books are essential reading for anyone interested in the specific technologies on which they focus; they give clear overviews of popular issues related to participatory media's role in shaping contemporary social and political relations.

While they provide excellent overviews of these issues, I'm not sure if either book provides the same grounding in how to think about technology as do both Radio in the Digital Age and Digital Media Ethics. In focusing on a specific technology or platform, Blogging and Twitter perpetuate a view that specific forms of social media can be parcelled out and isolated. As a result, they end up as limited, if focused, explorations of a single technology. They never quite make it to larger issues of context. These books are useful guides for their respective subjects, though their explanatory power is partial because of their focus-and neither Blogging nor Twitter has an explicitly political intention with its intellectual practice.

This is not the case for Graeme Kirkpatrick's Computer Games and the Social Imaginary. Unlike the other books in the New Media and Society series reviewed here, Computer Games and the Social Imaginary is explicitly a theoretical and political intervention into gaming as a technology that performs a specific form of social relation under contemporary capitalism. Drawing on the work of Luc Boltanski and Eve Chiapello, and echoing similar arguments made by Nick DyerWitheford, among others, Kirkpatrick makes a strong case for a critical theory of gaming, unmasking surface appearances of 'fun' and 'play' to reveal how games reproduce a way of imagining society that parallels and naturalises similar transformations in the contemporary operation of capitalism. Kirkpatrick draws on the history of computers to chronicle the rise in the popularity of the computer game and the birth of the 'gamer' as an identity category. He notes, in the process, the various articulations of sexism and cynicism that characterise the political 
relations embodied in gaming as a social and cultural act. Computer Games and the Social Imaginary is filled with countless insights, many of which I would imagine to be contested by those who self-identify as gamers-Kirkpatrick critiques this identity as something that veils deeply problematic and discriminatory relations of power. Gamers probably wouldn't be the only readers who disagree with Kirkpatrick. Critical theory and cultural studies, while often conflated because of similar theoretical touchstones, are not the same thing. Kirkpatrick's critique cuts directly to the fan practices that cultural studies scholars have often assumed to be resistant or empowering, demonstrating how these assumptions can negate the ability to recognise forms of oppression. Yet, at the same time, Kirkpatrick's book may seem to be telling well-worn narratives about capitalism and technology that go back to Adorno and Horkheimer. I would not disagree, though he draws our attention to the role capitalism and technology continue to play in organising and standardising everyday life-a fact that should not be neglected as often as it has been in cultural studies work on technology. But this brings us back to some of my earlier concerns. Are we stuck in repeating the same stories about technological control on one hand, given to us from critical theory and the medium theory of Marshall McLuhan, and audience empowerment on the other?

While I was a PhD student, one of the early historical narratives of cultural studies told to me involved the desire held by those at Birmingham to 'do sociology better than the sociologists'. Today's research on new media demonstrates that this goal was accomplished in a number of ways. Sociological work on new media and the internet regularly cite early cultural studies landmarks like Resistance Through Rituals and Subculture: The Meaning of Style; ${ }^{9}$ it often assumes that audiences are active; it examines the complex and varied practices of the everyday in shaping reality. These are all areas to which cultural studies work on media has directed us. Yet, while cultural studies has transformed sociology in many ways, the emphasis on new media and technology has now changed just what it means to study 'society' and 'culture'. We cannot assume technologies to be mere receptacles for human desires. At the same time, we cannot assume humans are completely determined by the technological. At its best, the books of Polity's Digital Media and Society series begin some of the work thinking beyond this impasse-Dubber's Radio in the Digital Age, especially. But, in the face of data metrics, evaluation frameworks and the 
professionalisation of education, in which the norms of the technological increasingly define and shape both teaching and research, one of the tasks of cultural studies should be to keep theorising technology in the classroom and in our writing, inventing new narratives, intervening through the production of new and different knowledge. For cultural studies to grasp the significance of technology in creating this world, in shaping knowledge and truth-for cultural studies to intervene in today's context-then we must rethink the stories we tell ourselves about humans and technological agency. We must once again do sociology better than the sociologists, and this time we must do it with the quantification of Big Data on the horizon.

Grant Bollmer is a lecturer in the Digital Cultures Program, Department of Media and Communication, at the University of Sydney. He has published articles in journals such as Cultural Studies, The Information Society and Memory Studies. He can be contacted via email at grant.bollmer@sydney.edu.au or over Twitter at @grantbollmer. 
9 Stuart Hall and Tony Jefferson (eds), Resistance Through Rituals: Youth Subcultures in Post-War Britain, Routledge, London, 1976; Dick Hebdige, Subculture: The Meaning of Style, Routledge, London, 1979.

\section{-BIBLIOGRAPHY}

Aiden, E. and Jean-Baptiste Michel, Uncharted: Big Data as a Lens on Human Culture, Riverhead Books, New York, 2013.

Bohannon, J., 'Google Opens Books to New Cultural Studies', Science, vol. 330, 2010, p. 1600. doi: http://dx.doi.org/10.1126/science.330.6011.1600

Golumbia, D., 'Computers and Cultural Studies', in Robert Kolker (ed.) The Oxford Handbook of Film and Media Studies, Oxford University Press, Oxford, 2008.

Grossberg, L., Cultural Studies in the Future Tense, Duke University Press, Durham, 2010. doi: http://dx.doi.org/10.1215/9780822393313

Hall, S. and T. Jefferson (eds), Resistance Through Rituals: Youth Subcultures in Post-War Britain, Routledge, London, 1976.

Hebdige, D., Subculture: The Meaning of Style, Routledge, London, 1979.

Kolker, R. (ed.), The Oxford Handbook of Film and Media Studies, Oxford University Press, Oxford, 2008. doi: http://dx.doi.org/10.1093/oxfordhb/9780195175967.001.0001

Mayer, V., Below the Line: Producers and Production Studies in the New Television Economy, Duke University Press, Durham, 2011. doi: http://dx.doi.org/10.1215/9780822394136

Michel, J-B., Y. K. Shen, A. Presser Aiden, A. Veres, M. K. Gray, The Google Books Team, J. P. Pickett, D. Hoiberg, D. Clancy, P. Norvig, J. Orwant, S. Pinker, M. A. Nowak and E. Lieberman Aiden, 'Quantitative Analysis of Culture Using Millions of Digitized Books', Science, vol. 331, 2011.

Readings, B., The University in Ruins, Harvard University Press, Cambridge, MA, 1996. 